This is the author's final, peer-reviewed manuscript as accepted for publication. The publisher-formatted version may be available through the publisher's web site or your institution's library.

\title{
Complement component C5a mediates hemorrhage-induced intestinal damage
}

Sherry D. Fleming, Lauren M. Phillips, John D. Lambris, and George C. Tsokos

\section{How to cite this manuscript}

If you make reference to this version of the manuscript, use the following information:

Fleming, S. D., Phillips, L. M., Lambris, J. D., \& Tsokos, G. C. (2008). Complement component $\mathrm{C} 5 \mathrm{a}$ mediates hemorrhage-induced intestinal damage. Retrieved from http://krex.ksu.edu

\section{Published Version Information}

Citation: Fleming, S. D., Phillips, L. M., Lambris, J. D., \& Tsokos, G. C. (2008). Complement component C5a mediates hemorrhage-induced intestinal damage. Journal of Surgical Research, 150(2), 196-203.

Copyright: (c) 2008 Elsevier Inc.

Digital Object Identifier (DOI): doi:10.1016/j.jss.2008.02.010

Publisher's Link: http://www.sciencedirect.com/science/article/pii/S0022480408000887

This item was retrieved from the K-State Research Exchange (K-REx), the institutional repository of Kansas State University. K-REx is available at http://krex.ksu.edu 


\title{
Complement component C5a mediates hemorrhage-induced
}

\section{intestinal damage}

\author{
Sherry D. Fleming ${ }^{* 1,2}$, Lauren M. Phillips ${ }^{* 3}$, John D. Lambris ${ }^{\dagger}$, and George C, Tsokos ${ }^{\ddagger}$ \\ *Division of Biology, Kansas State University, Manhattan, KS 66506 \\ ${ }^{\dagger}$ Pathology and Laboratory Medicine, University of Pennsylvania, Philadelphia, PA \\ ${ }^{\ddagger}$ Division of Rheumatology, Beth Israel Deaconess Medical Center, Harvard Medical \\ School, Boston, MA
}

Running title: C5a mediates hemorrhage-induced intestinal damage

Subject Category: Gastrointestinal

Corresponding Author:

Sherry Fleming

18Ackert Hall

Kansas State University

Manhattan, KS 66506

785-587-9602

sdflemin@ksu.edu 


\begin{abstract}
Background: Complement has been implicated in the pathogenesis of intestinal damage and inflammation in multiple animal models. Although the exact mechanism is unknown, inhibition of complement prevents hemodynamic alterations in hemorrhage.

Materials/Methods: $\mathrm{C} 57 \mathrm{Bl} / 6$, complement 5 deficient (C5-/-) and sufficient (C5+/+) mice were subjected to 25\% blood loss. In some cases, C57Bl/6 mice were treated with C5a receptor antagonist (C5aRa) post-hemorrhage. Intestinal injury, leukotriene B4, and myeloperoxidase production were assessed for each treatment group of mice.

Results: Mice subjected to significant blood loss without major trauma develop intestinal inflammation and tissue damage within two hours. We report here that complement 5 (C5) deficient mice are protected from intestinal tissue damage when subjected to hemorrhage (Injury score $=0.36$ compared to wildtype hemorrhaged animal injury score $=2.89 ; \mathrm{p}<0.05$ ). We present evidence that C5a represents the effector molecule because $\mathrm{C} 57 \mathrm{Bl} / 6$ mice treated with a $\mathrm{C} 5 \mathrm{a}$ receptor antagonist displayed limited intestinal injury (Injury score $=0.88$ ), leukotriene B4 (13.16 pg/mg tissue) and myeloperoxidase (115.6 pg/mg tissue) production compared to hemorrhaged C57Bl/6 mice ( $\mathrm{p}<0.05)$.

Conclusion: Complement activation is important in the development of hemorrhage-induced tissue injury and C5a generation is critical for tissue inflammation and damage. Thus, therapeutics targeting C5a may be useful therapeutics for hemorrhage-associated injury.
\end{abstract}

Keywords: complement, mucosa, rodent 


\section{Introduction}

Hemorrhage and the accompanying hemorrhagic shock result in clinical complications and systemic inflammation $(1,2)$. During hemorrhage, there is decreased systemic perfusion leading to decreased blood flow to the intestine, kidney and skeletal muscle $(3,4)$. As the intestine normally receives more blood from the heart than any other organ with the splanchnic circulation consisting of up to $25-30 \%$ of the total blood volume, hemorrhage-induced decreased intestinal blood flow and associated vasoconstriction, may result in a functional intestinal ischemia (5). In other models of ischemia, this process leads to local and systemic damage and is suggested to be critical in the induction of multiple organ failure (6). Mechanisms of ischemia and subsequent reperfusion-induced intestinal mucosal injury include oxidative stress and excessive complement activation (7-9).

Excessive complement activation results in tissue damage in many animal models including septic shock, transplantation and mesenteric or skeletal muscle ischemia (reviewed in (10)). Previously, we showed that C5a has a significant role in a mouse model of intestinal ischemia/reperfusion-induced damage and eicosanoid production (8). In addition, others have shown that C5 and specifically, C5a, is critical for neutrophil and monocyte chemotaxis in either myocardial or mesenteric ischemic models (11-14). Finally, in a renal ischemia/reperfusion model, C5a blockade prevents damage that is not dependent on neutrophil infiltration, but by alteration of the chemokine profile (13). Thus, therapeutics which target complement activation in the intestine prevent damage in other animal models and the same therapeutics may be beneficial in hemorrhage. 
Complement activation is also critical in rat models of hemorrhagic shock. . Depletion of complement prevented clinical signs of hemorrhagic shock (15) and hemodynamic changes were prevented with complement inhibition with soluble complement receptor 1 (sCR1) $(3,16)$ or C1inhibitor (17). Recent studies showed that anti-C5 antibody treatment decreases the resuscitation fluid volume required to improve mean arterial pressure (18). Total inhibition of complement activation and the membrane attack complex, however, may lead to sepsis and other infectious complications due to the inhibition of all complement cascades. It is critical therefore, to identify the specific molecules involved in the complement mediated damage in order to achieve targeted complement inhibition. Excess of C5a is lethal in a rat hemorrhage model (15) and a C5a receptor antagonist decreased the inflammatory response within rat intestine and lungs in a model of intestinal ischemia with hemorrhage (19). However, it is unclear if inhibition of C5a activity is sufficient to prevent or attenuate intestinal damage and its sequelae.

Many animal models of hemorrhage involve rats and include traumatic injury (19-24) and the use of heparin $(3,16)$ which complicates determination of the complement activation factors. In addition, rat models of hemorrhagic shock preclude the use of genetically modified animals. Here we show that in the absence of major trauma, loss of one-quarter of the total blood volume in mice results in significant intestinal inflammation and damage. We present evidence that C5 deficient mice do not develop signs of inflammation and tissue damage and more importantly, blockade of the action of C5a with a synthetic C5a receptor antagonist limited tissue damage in wild type mice. 


\section{Materials and Methods:}

Mice- C57Bl/6, B10.D2-Hc ${ }^{0} \mathrm{H}{ }^{\mathrm{d}} \mathrm{H} 2-\mathrm{T} 18^{\mathrm{c}} / \mathrm{oSnJ}$ and B10.D2-Hc ${ }^{1} \mathrm{H}{ }^{\mathrm{d}} \mathrm{H} 2-\mathrm{T} 18^{\mathrm{c}} / \mathrm{nSnJ}$ (C5-/and C5+/+, respectively) male mice (6-8 wks old) were obtained from Jackson Laboratories (C5+/+, and C5-/-) or bred (C57Bl/6) and maintained in the Division of Biology at Kansas State University. All mice were allowed food and water ad libitum and kept in 12-hour light-to-dark facilities. Research was conducted in compliance with the Animal Welfare Act and other federal statutes and regulations relating to animals and experiments involving animals and experiments were performed according to the principles set forth in the Guide for the Care and Use of Laboratory Animals (Institute of Laboratory Animal Resources, National Research Council, 1996 edition).

Hemorrhage Protocol: After a 1 week acclimatization period, mice were anesthetized using ketamine (16 mg/kg) and xylazine (80 mg/kg). All procedures were performed with the animals breathing spontaneously and body temperature maintained at $37^{\circ} \mathrm{C}$ using a water-circulating heating pad. Mice undergoing hemorrhage were subjected to retro-orbital removal of $25 \%$ of the calculated blood volume (approximately $0.5 \mathrm{ml}$ ) over a $90 \mathrm{sec}$ period $(25,26)$. Volume of blood to be removed was based on weight and ranged from $400 \mathrm{ul}$ to $600 \mathrm{ul}$; (body weight in grams $\mathrm{x}$ 0.02 (27)). The determined blood volume was measured in water and marked on both the collection tubes and the capillary tubing used for retro-orbital punctures. This ensured that the correct amount would be withdrawn. A single retro-orbital puncture was sufficient for blood collection. The $2 \mathrm{hr}$ mortality rate was less than 1\%. Sham mice were subjected to similar procedures with no blood removal. In some studies, the murine C5aRa (25 $\mu \mathrm{g} / \mathrm{mouse}$ ) was 
injected intravenously 5-15 min after either hemorrhage or sham treatment (28). An additional experimental group consisted of mice subjected to hemorrhage followed one hour later by administration of $200 \mu \mathrm{l}$ normal saline i.v. Control animals for this group received an equal volume of sterile phosphate buffered saline (PBS). C5aRa was synthesized and similar dosages administered as described previously (28). To prevent spontaneous complement activation, all studies were performed in the absence of heparin. At $2 \mathrm{hr}$ post-hemorrhage, mice were euthanized and tissues collected for analysis. Intestinal tissues were formalin fixed for analysis of injury and frozen sections were obtained for immunohistochemistry.

Injury Score: Formalin fixed tissue sections were transversely sectioned and $\mathrm{H}+\mathrm{E}$ stained for analysis of injury. Injury was scored by an observer unaware of the treatment given using a sixtiered scale adapted from Chiu et al. that was described previously $(7,8,29)$. The average damage score was assigned to an approximately $2 \mathrm{~cm}$ section of mid-jejunum intestine (75-150 villi) after grading each villus from $0-6$. Normal villi were assigned a score of zero; villi with tip distortion were assigned a score 1; score 2 was assigned when Guggenheims’ spaces are present; villi with patchy disruption of the epithelial cells were assigned a score of 3; score 4 was assigned to villi with exposed but intact lamina propria with epithelial sloughing; a score of 5 was assigned when the lamina propria was exuding; last, villi that display hemorrhage or denuded were assigned a score of 6 .

Villus Height/ Crypt Depth: Villus height/ crypt depth ratio of at least 15 individual villi per animal was measured using Metavue computer software (Molecular Devices, Sunnyvale, CA). The average of 3-8 animals per treatment group is reported. 
Leukotriene B4, myeloperoxidase and total peroxidase production: Ex vivo intestinal supernatants were generated for total peroxidase, leukotriene $\mathrm{B}_{4}\left(\mathrm{LTB}_{4}\right)$ and myeloperoxidase (MPO) analysis as described previously (30, 31). Briefly, $1 \mathrm{~cm}$ mid-jejunum sections were minced, washed and resuspended in oxygenated Tyrode’s buffer (Sigma, St. Loius, MO) for 20 $\min$ at $37^{\circ} \mathrm{C}$. Following incubation, the supernatants and tissues were collected and stored in $80^{\circ} \mathrm{C}$ until assayed. Commercially available LTB 4 EIA kit (Cayman Chemicals \#520111, Ann Arbor, MI) and MPO specific ELISA kit (Cell Sciences, \#HK201 Canton, MA) were used to determine $\mathrm{LTB}_{4}$ and MPO concentrations. Total tissue peroxidase was determined by incubating supernatants with 3, 3’, 5, 5’ tetramethylbenzedene (TMB) (KPL Chemicals, Rockville, MD) and the reaction stopped with $0.18 \mathrm{M}$ sulfuric acid. The OD450 was determined and compared with a horseradish peroxidase (Sigma) standard. The concentration of each factor was reported as pg/mg intestinal tissue.

Immunohistochemistry. Tissues snap frozen in TBS freezing media (ThermoFisher, Waltham, MA) were sectioned at 6-8 $\mu$ for immunohistochemistry staining as described previously $(7,8)$. Briefly, nonspecific antibody binding sites were blocked by treatment with a solution of 20\% rabbit serum (Jackson ImmunoResearch, West Grove, PA) in PBS for 30 minutes prior to incubation with rabbit anti-mouse C3 antibody (Cell Sciences \#HP8012) overnight at $4^{\circ} \mathrm{C}$. The tissue was then incubated with donkey anti-rabbit secondary antibody conjugated to Texas Red (Jackson ImmunoResearch). After washing, the slides were mounted with ProLong Gold (Invitrogen, Carlsbad, CA). A blinded observer examined the slides by fluorescent microscopy using a Nikon 80i fluorescent microscope equipped with appropriate filters and CoolSnapCf 
camera (Photometrics, Tucson, AZ)and analyzed by MetaVue Imaging software (Molecular Devices).

Statistics. The data are presented as mean \pm SEM and compared by one-way ANOVA with Neuman-Keuls post-hoc analysis (GraphPad, San Diego, CA). Differences were considered significant when $\mathrm{p}<0.05$. 


\section{RESULTS}

\section{Hemorrhage induces intestinal damage}

A recent study showed that during porcine hemorrhage, intestinal blood flow decreased proportionally to total volume, but these studies did not examine the extent of intestinal damage (4). To confirm that blood loss induced intestinal damage, mice were sham-treated or retroorbitally bled to remove $25 \%$ blood volume. Previous reports indicated that removal of 25\% blood volume induced liver damage and inflammation and preliminary data indicated the presence of significant intestinal damage. Intestinal tissues were collected $2 \mathrm{hr}$ post bleeding and analyzed for mucosal injury. As shown in Fig. 1A, and D, sham treatment did not result in damage of the intestines as indicated by preservation of villi tips (Fig. 1A) and low injury score (Fig. 1D). In contrast, significant mucosal damage occurred at $2 \mathrm{hr}$ post hemorrhage as shown in Fig. 1B and 1D. Intestinal damage at $2 \mathrm{hr}$ post hemorrhage included disintegration of the epithelial integrity, exuding lamina propria from the villi (Fig. 1B) which resulted in increased injury score (Fig. 1D). Also, indicative of damage, hemorrhage resulted in significantly shorter villi without altering the crypt depth as indicated by villus height/crypt depth ratio (Fig. 1E). As resuscitation with even small volumes of saline, may alter damage and inflammation, some groups of both sham and hemorrhaged mice were administered 200ul normal saline i.v. As

indicated in Fig. 1C, 1D and 1E, small volumes of normal saline at $1 \mathrm{hr}$ post hemorrhage did not alter the injury score ( $\mathrm{p}=0.092)$, or villus height vs. crypt depth ratio (Fig. 1C, 1D and 1E).

\section{Intestinal damage and inflammation is complement-dependent}

As other forms of intestinal mucosal damage are complement mediated, we assessed C3 deposition on the intestine of mice subjected to hemorrhage by immunofluorescence (Fig. 2). 
Significant amounts of C3 were deposited on the intestinal tissues of hemorrhaged mice (Fig. 2B), whereas no C3 was deposited to the intestines of sham-treated mice (Fig. 2A).

To investigate if complement has a critical role in hemorrhage-induced intestinal damage, C5 deficient (C5-/-) mice and C5 sufficient mice $(C 5+/+)$ were subjected to hemorrhage and intestinal injury assessed $2 \mathrm{hr}$ later. As shown in Fig. 3A, sham treatment did not induce intestinal damage in either strain. Similar to C57Bl/6 mice, the complement sufficient mice subjected to hemorrhage developed significant intestinal damage (Fig. 3A, B) manifested by increased injury scores and decreased villus height/crypt depth ratio compared to sham-treated mice. In contrast, hemorrhage-induced, intestinal damage was significantly attenuated in C5-/mice compared to the $C 5+/+$ mice with mean injury scores of 0.36 and 2.89, respectively (Fig. 3A, B and C). Villi remained tall, the villus height/crypt depth ratio did not change and the epithelial layer remained intact in C5-/- mice after hemorrhage (Fig. 3C). As expected, C3 was deposited in both $\mathrm{C5}+/+$ and $C 5-/-$ mice despite the lack of damage (data not shown).

Excessive inflammation, characterized by neutrophil infiltration, mediates hemorrhage induced liver and lung injury $(17,26,32)$. To determine if hemorrhage induces intestinal neutrophil infiltration, the production of chemotactic factor LTB 4 was determined. As shown in Fig.4A hemorrhage induced significant $\mathrm{LTB}_{4}$ production. In addition, intestinal tissues from hemorrhaged, complement sufficient mice contained increased amounts of myeloperoxidase when compared with sham-treated mice (Fig. 4B). In contrast, when C5-/- mice were subjected to hemorrhage, the release of $\mathrm{LTB}_{4}$ was significantly reduced, suggesting that the recruitment of 
neutrophils to the intestine is complement dependent (Fig. 4A). In addition, intestinal tissue from C5-/- mice subjected to hemorrhage did not contain any myeloperoxidase (Fig. 4B).

\section{C5a receptor antagonist attenuates intestinal damage and inflammation}

We considered it likely that C5a generated following complement activation is responsible for the observed neutrophil infiltration in C5 sufficient mice subjected to hemorrhage and that inhibition of its action would limit the inflammatory response and tissue damage. To test this possibility we treated male C57Bl/6 mice with murine C5a receptor antagonist or an equivalent volume of PBS 5-10 min after hemorrhage. In contrast to the PBS-treated C57Bl/6 mice (Fig. 5B), mice injected with C5a receptor antagonist displayed attenuated intestinal mucosal damage (Fig. 5C) with pathology similar to that recorded in the sham group of animals (Fig. 5A). Hemorrhage-induced intestinal injury was decreased significantly in C5a receptor antagonist treated mice compared to the PBS-treated group of hemorrhaged mice and was comparable to tissue injury observed in the sham group of mice (Fig. 5D). C5a production occurs downstream of C3 activation; therefore, C5a receptor antagonist should not alter C3 deposition. C5a receptor antagonist treatment did not limit the amounts of C3 deposited to the intestine of hemorrhaged mice (Figs. 2 and 6) and the observed C3 deposition in these mice was increased compared to the sham group of animals (Fig. 6A,B). As expected, administration of C5a receptor antagonist decreased LTB4 production in both sham and hemorrhaged mice (Fig. 7A) and eliminated the hemorrhage-induced increase in myeloperoxidase content (Fig. 7B). Together these data indicate that C5a receptor antagonist can attenuate the hemorrhage-induced chemotactic activity and intestinal tissue damage. 


\section{Discussion}

Hemorrhage induces intestinal mucosal damage and inflammation with complement activation and influx of neutrophils $(3,16)$. Complement inhibition prevents intestinal damage and decreases vasoconstriction and the subsequent requirement for fluid to maintain the mean arterial pressure $(18,19,33)$. Our study shows that low blood volume also leads to intestinal damage and inflammation in complement sufficient but not in C5 deficient mice. C5a which is produced during complement activation appears to be the culprit because inhibition of its action by C5a receptor antagonist limits both the inflammatory response and intestinal tissue damage.

Complement is known to have a role in the intestinal damage, but the specific pathway or molecules involved are unknown. In ischemia and sepsis models of intestinal damage, C5a has been shown to be required for neutrophil infiltration $(8,14,19,34,35)$. Inhibition of C3a and C5a in rat models of hemorrhage or hemorrhage with vascular clamping prevented decrease in mean arterial pressure and the appearance of acidosis, intestinal permeability and tissue damage $(15,19)$. Our studies extend these observations and suggest the recorded beneficiary effects of complement inhibition on physiological parameters such as mean arterial blood pressure and acid-base balance are probably due to the preceding inhibition of the tissue inflammatory response and damage. Indeed, the administration of C5a receptor antagonist limited the production of the chemotactic factor, $\mathrm{LTB}_{4}$, and the infiltration of the intestinal tissue by neutrophils as manifested by decreased myeloperoxidase content. C5a receptor antagonist has been shown to be effective in other animal models of inflammation (35, 36), including a murine model of mesenteric ischemia/reperfusion (8). 
It is possible that the administration of C5 receptor antagonist alters the cytokine milieu that leads to intestinal damage. Previous studies have illustrated that monocytes treated with C5a produce IL-6 (37). Other studies have shown that hemorrhage increases KC, MCP-1, IL-6 and IL-10 serum concentrations in a TLR4-dependent manner (22, 38, 39). In addition, Meng et.al. showed that IL-6 is critical for the induction of lung and liver damage in response to hemorrhage (32). Therefore, IL-6 and possibly other cytokines or chemokines may be involved in hemorrhage-induced intestinal damage and it is possible that C5a receptor antagonist alters the inflammatory cytokine response.

In many animal models, C5a and selective C5a agonists induce hypotension and vascular permeability that is inhibited by blockade of C5a receptor binding $(19,33)$. In other animal models, C5a receptor antagonists attenuate the cobra venom factor mediated or xenotransplant induced blood pressure changes $(40,41)$. However, in other hemorrhage studies, complement depletion did not significantly alter mean arterial pressures within the first $2 \mathrm{hr}$ after hemorrhage (15). Thus, it is possible that administration of the $\mathrm{C} 5$ receptor antagonist prevents the hemorrhage-induced hypotension. Additional studies will be needed to determine the exact mechanism of protection provided by the C5a receptor antagonist.

Previous studies have shown that complement inhibition prevents intestinal damage and decreased vasoconstriction in rat models of hemorrhage $(3,16)$. In a rat model of hemorrhage and mesenteric ischemia, the combination of heparin and C5a receptor antagonist decreased intestinal permeability and tumor necrosis factor production (19). The unavoidable use of 
heparin in practically all hemorrhage models complicates the interpretation of the data because of the extensive interaction of the complement and coagulation activation cascades (42). Our studies offer a unique model to study the role of complement activation in a murine model of hemorrhage without the interference of confounding factors such as trauma, tubing and the need for anti-coagulation drugs.

In conclusion, we present evidence in a simple model of murine hemorrhage which does not involve the use of trauma or anti-coagulants that complement activation is responsible for inflammation and tissue damage in the intestine. C5 deficient mice were found to be completely protected from hemorrhage-induced intestinal damage and the administration of a C5a receptor antagonist limits both the inflammatory response and tissue damage in the intestine of mice subjected to hemorrhage. The use of complement inhibitors may therefore be of clinical value in people who hemorrhage and they may limit the need for resuscitation fluids. 


\section{Acknowledgements}

1. The authors thank Ms. Tiffany Moses and Diana Hylton for their technical expertise. 


\section{References}

1. DeBakey, M. E., and Simeone, F. A. Battle injuries of the arteries in World War II: an analysis of 2,471 cases. Ann. Surg. 123: 534-579, 1946.

2. Bellamy, R. F. The causes of death in conventional land warfare:implications for combat casulty care research. Mil. Med. 149: 55-62, 1984.

3. Fruchterman, T. M., Spain, D. A., Wilson, M. A., Harris, P. D., and Garrison, R. N. Complement inhbition prevents gut ischemia and endothelial cell dysfunction after hemorrhage/resuscitation. Surgery. 124: 782-792, 1998.

4. Kvarstein, G., Mirtheri, P., and Tonnessen, T. I. Detection of organ ischemia during hemorrhagic shock. Acta Anaesthesiol. Scand.: 675-686, 2003.

5. Shea-Donohue, T., Anderson, J., and Swiecki, C. Ischemia/reperfusion injury. In G. C. Tsokos, and J. L. Atkins (Eds.), Combat Medicine, Totowa, New Jersey: Humana Press, 2003. Pp. 219-248.

6. Tavaf-Motamen, H., Miner, T. J., Starnes, B. W., and Shea-Donohue, T. Nitric oxide mediates acute lung injury by modulation of inflammation. J. Surg. Res. 78: 137-142, 1998. 7. Fleming, S. D., Anderson, J., Wilson, F., Shea-Donohue, T., and Tsokos, G. C. C5 is required for CD49d expression on neutrophils and VCAM expression on vascular endothelial cells following mesenteric ischemia/reperfusion. Clin. Immunol. 105: 55-64, 2003.

8. Fleming, S. D., Mastellos, D., Karpel-Massler, G., Shea-Donohue, T., Lambris, J. D., and Tsokos, G. C. C5a causes limited, polymorphonuclear cell-independent, mesenteric ischemia/reperfusion-induced injury. Clin. Immunol. 108: 263-273, 2003.

9. Rehrig, S., Fleming, S. D., Anderson, J., Guthridge, J. M., Rakstang, J., McQueen, C. E., Holers, V. M., Tsokos, G. C., and Shea-Donohue, T. Complement inhibitor, complement 
receptor 1-related gene/protein y-Ig attenuates intestinal damage after the onset of mesenteric ischemia/reperfusion injury in mice. J. Immunol. 167: 5921-5927, 2001.

10. Fleming, S. D., and Tsokos, G. C. Complement Inhibitors in Rheumatic Diseases. In G. C. Tsokos (Ed.), Modern therapeutics in Rheumatic Diseases, Totowa, NJ: Humana Press, 2000. Pp. 443-452.

11. Birdsall, H. H., Green, D. M., Trial, J., Youker, K. A., Burns, A. R., MacKay, C. R., LaRosa, G. J., Hawkins, H. K., Smith, C. W., Michael, L. H., Entman, M. L., and Rossen, R. D. Complement C5a, TGF-beta1, and MCP-1, in sequence, induce migration of monocytes into ischemic canine myocardium within the first one to five hours after reperfusion. Circulation. 95: 684-692, 1997.

12. Ivey, C. L., Williams, F. M., Collins, P. D., Jose, P. J., and Williams, T. J. Neutrophil chemoattractants generated in two phases during reperfusion of ischemic myocardium in the rabbit: evidence for a role for C5a and interleukin-8. J. Clin. Invest. 95: 2720-2728, 1995.

13. de Vries, B., Kohl, J., Leclercq, W. K. G., Wolfs, T. G. A. M., van Bijnen, A. A. J. H. M., Heeringa, P., and Buurman, W. A. Complement factor C5a mediates renal ischemia-reperfusion injury independent of neutrophils. J. Immunol. 170: 3883-3889, 2003.

14. Arumugam, T. V., Shiels, I. A., Woodruff, T. M., Reid, R. C., Fairlie, D. P., and Taylor, S. M. Protective effect of a new C5a receptor antagonist against ischemia-reperfusion injury in the rat small intestine. J. Surg. Res. 103: 260-267, 2002.

15. Younger, J. G., Sasaki, N., Waite, M. D., Murray, H. N., Saleh, E. F., Ravage, Z. A., Hirschl, R. B., Ward, P. A., and Till, G. O. Detrimental effects of complement activation in hemorrhagic shock. J. Appl. Physiol. 90: 441-446, 2001. 
16. Spain, D. A., Fruchterman, T. M., Matheson, P. J., Wilson, M. A., Martin, A. W., and Garrison, R. N. Complement activation mediates intestinal injury after resuscitation from hemorrhagic shock. J. Trauma. 46: 224-233, 1999.

17. Horstick, G., Kempf, T., Lauterbach, M., Bhakdi, S., Kopacz, L., Heimann, A., Malzahn, M., Horstick, M., Meyer, J., and Kempski, O. C1-esterase-inhibitor treatment at early reperfusion of hemorrhagic shock reduces mesentry leukocyte adhesion and rolling. Microcirculation. 8: 427-433, 2001.

18. Peckham, R. M., Handrigan, M. T., Bentley, T. B., Falabella, M. J., Chrovian, A. D., Stahl, G. L., and Tsokos, G. C. C5-blocking antibody reduces fluid requirements and improves responsiveness to fluid infusion in hemorrhagic shock managed with hypotensive resuscitation. J. Appl. Physiol. 102: 673-680, 2007.

19. Harkin, D. W., Romaschin, A., Taylor, S. M., Rubin, B. B., and Lindsay, T. F. Complement C5a receptor antagonist attenuates multiple organ injury in a model of ruptured abdominal aortic aneurysm. J. Vasc. Surg. 39: 196-206, 2004.

20. Homma, H., Deitch, E. A., Feketeova, E., Lu, Q., Berezina, T. L., Zaets, S. B., Machiedo, G. W., and Xu, D. Z. Small volume resuscitation with hypertonic saline is more effective in ameliorating trauma-hemorrhagic shock-induced lung injury, neutrophil activation and red blood cell dysfunction than pancreatitic protease inhibition. J. Trauma. 59: 266-272, 2005.

21. Kiang, J. G., Peckham, R. M., Duke, L. E., Shimizu, T., Chaudry, I. H., and Tsokos, G. C. Androstenediol inhibits the trauma-hemorrhage-induced increase in caspase-3 by downregulating the inducible nitric oxide synthase pathway. J. Appl. Physiol. 102: 933-941, 2007. 
22. Thobe, B. M., Frink, M., Hildebrand, F., Schwacha, M. G., Hubbard, W. J., Choudhry, M. A., and Chaudry, I. H. The role of MAPK in Kupffer cell toll-like receptor (TLR) 2-, TLR4-, and TLR9-mediated signaling following trauma-hemorrhage. J. Cell. Physiol. 210: 667-675, 2007.

23. Hildebrand, F., Thobe, B. M., Hubbard, W. J., Choudhry, M. A., Pape, H. C., and Chaudry, I. H. Effects of 17beta-estradiol and flutamide on splenic macrophages and splenocytes after trauma-hemorrhage. Cytokine. 36: 107-114, 2006.

24. Hildebrand, F., Hubbard, W. J., Choudhry, M. A., Frink, M., Pape, H. C., Kunkel, S. L., and Chaudry, I. H. Kupffer cells and their mediators: the culprits in producing distant organ damage after trauma-hemorrhage. Am. J. Pathol. 169: 784-794, 2006.

25. Lomas-Niera, J. L., Perl, M., Chung, C.-S., and Ayala, A. Shock and hemorrhage; An overview of animal models. Shock. 24: 33-39, 2005.

26. Arcaroli, J., Yang, K. Y., Yum, H. K., Kupfner, J., Pitts, T. M., Park, J. S., Strassheim, D., and Abraham, E. Effects of catecholamines on kinase activation in lung neutrophils after hemorrhage or endotoxemia. J. Leukoc. Biol. 72: 571-579, 2002.

27. Rajnik, M., Salkowski, C. A., Thomas, K. E., Li, Y. Y., Rollwagen, F. M., and Vogel, S. N. Induction of early inflammatory gene expression in a murine model of nonresuscitated, fixedvolume hemorrhage. Shock. 17: 322-328, 2002.

28. Mastellos, D., Papadimitriou, J. C., Franchini, S., Tsonis, P. A., and Lambris, J. D. A novel role of complement: mice deficient in the fifth component of complement (C5) exhibit impaired liver regeneration. J. Immunol. 166: 2479-2486, 2001.

29. Chiu, C.-J., McArdle, A. H., Brown, R., Scott, H. J., and Gurd, F. N. Intestinal mucosal lesion in low-flow states. Arch. Surg. 101: 478-483, 1970. 
30. Fleming, S. D. Natural antibodies, autoantibodies and complement activation in tissue injury. Autoimmunity. 39: 379-386, 2006.

31. Fleming, S. D., Monestier, M., and Tsokos, G. C. Accelerated ischemia/reperfusioninduced injury in autoimmunity-prone mice. J. Immunol. 173: 4230 - 4235, 2004.

32. Meng, Z. H., Dyer, K., Billiar, T. R., and Tweardy, D. J. Essential role for IL-6 in postresuscitation inflammation in hemorrhagic shock. Am J Physiol Cell Physiol. 280: C343-351, 2001.

33. Harkin, D. W., Marron, C. D., Rother, R. P., Romaschin, A., Rubin, B. B., and Lindsay, T. F. C5 complement inhibition attenuates shock and acute lung injury in an experimental model of ruptured abdominal aortic aneurysm. Br. J. Surg. 92: 1227-1234, 2005.

34. Czermak, B. J., Sarma, V., Pierson, C. L., Warner, R. L., Huber-Lang, M., Bless, N. M., Schmal, H., Friedl, H. P., and Ward, P. A. Protective effects of C5a blockade in sepsis. Nat. Med. 5: 788-792, 1999.

35. Riedemann, N. C., Guo, R. F., Neff, T. A., Laudes, I. J., Keller, K. A., Sarma, J. V., Markiewski, M. M., Mastellos, D., Strey, C. W., Pierson, C. L., Lambris, J. D., Zetoune, F. S., and Ward, P. A. Increased C5a receptor expression in sepsis. J. Clin. Invest. 110: 101-108, 2002. 36. Heller, T., Hennecke, M., Baumann, U., Gessner, J. E., Meyer zu Vilsendorf, A., Baensch, M., Boulay, F., Kola, A., Klos, A., Bautsch, W., and Kohl, J. Selection of a C5a receptor antagonist from phage libraries attenuating the inflammatory response in immune complex disease and ischemia/reperfusion injury. J. Immunol. 163: 985-994, 1999.

37. Fayyazi, A., Scheel, O., Werfel, T., Schweyer, S., Oppermann, M., Gotze, O., Radzun, H. J., and Zwirner, J. The C5a receptor is expressed in normal renal proximal tubular but not in normal pulmonary or hepatic epithelial cells. Immunology. 99: 38-45, 2000. 
38. Prince, J. M., Levy, R. M., Yang, R., Mollen, K. P., Fink, M. P., Vodovotz, Y., and Billiar, T. R. Toll-like receptor-4 signaling mediates hepatic injury and systemic inflammation in hemorrhagic shock. Journal of American College Surgery. 202: 407-417, 2006.

39. Frink, M., Lu, A., Thobe, B. M., Hsieh, Y. C., Choudhry, M. A., Schwacha, M. G., Kunkel, S. L., and Chaudry, I. H. Monocyte chemoattractant protein-1 influences traumahemorrhage-induced distal organ damage via regulation of keratinocyte-derived chemokine production. Am J Physiol Regul Integr Comp Physiol. 292: R1110-1116, 2007.

40. Gaca, J. G., Appel, J. Z., 3rd, Lukes, J. G., Gonzalez-Stawinski, G. V., Lesher, A., Palestrant, D., Logan, J. S., Love, S. D., Holzknecht, Z. E., Platt, J. L., Parker, W., and Davis, R. D. Effect of an anti-C5a monoclonal antibody indicates a prominent role for anaphylatoxin in pulmonary xenograft dysfunction. Transplantation. 81: 1686-1694, 2006.

41. Proctor, L. M., Strachan, A. J., Woodruff, T. M., Mahadevan, I. B., Ming Williams, H., Shiels, I. A., and Taylor, S. M. Complement inhibitors selectively attenuate injury following administration of cobra venom factor to rats. International Immunopharmacology. 6: 1224, 2006. 42. Markiewski, M. M., Nilsson, B., Ekdahl, K. N., Mollnes, T. E., and Lambris, J. D. Complement and coagulation: strangers or partners in crime? Trends Immunol. 28: 184-192, 2007. 


\section{Footnotes}

1. Corresponding Author:
Sherry Fleming
18Ackert Hall
Kansas State University
Manhattan, KS 66506
785-587-9602
sdflemin@ksu.edu

2. This study was supported by the following: a grant from the Dept. of Defense, NIH Grants GM-62134, and P20-RR017686 and P20-RR016475 from the Institutional Development Award (IDeA) Program of the NCRR, HHMI Undergraduate Science Educational Grant, Terry C. Johnson Center for Cancer Research, and the Division of Biology, Kansas State University. 3. L.P. was supported as an HHMI Undergraduate Scholar.

4. The opinions or assertions contained herein are the private views of the authors and are not to be construed as official or reflecting the views of the US Department of the Army, or the US Department of Defense. 


\section{Figure Legends:}

Figure 1. Hemorrhage induces intestinal injury. Wildtype mice which were subjected to sham treatment (A) or hemorrhage (B) followed by a 2 hour recovery period. Intestinal sections were stained with $\mathrm{H}+\mathrm{E}$. Additional mice were subjected to hemorrhage followed by an injection of normal saline (C). Formalin fixed intestinal sections from each treatment group were scored for mucosal injury (0-6) as described in Materials and Methods (D). Open bars represent no resuscitation fluid, solid bars represent resuscitation fluids were administered. Each bar represents the average \pm SEM with 4-10 mice per group. Villus height/ crypt depth ratio of individual villi was measured using Metavue computer software (E). All measurements were obtained at a x200 magnification. Open bars represent no normal saline, solid bars represent normal saline was administered. Each bar is the average \pm SEM with 3 mice per group. Using ANOVA with Newman-Keuls post hoc test, the asterisk indicates significant difference from the respective sham treatment group ( $p \leq 0.05)$.

Figure 2. C3 is deposited to intestinal tissue following hemorrhage. Intestinal sections from wildtype mice subjected to sham treatment (A) or hemorrhage (B) and were stained for C3 deposition as described in Materials and Methods. Original magnification is x200. Data are representative of three individual experiments.

\section{Figure 3. Hemorrhage-induced intestinal damage is attenuated in C5 deficient mice.}

Formalin fixed intestinal sections from each group were scored for mucosal injury (0-6) as described in Materials and Methods (A). Each dot represents a single animal. $\mathrm{H}+\mathrm{E}$ intestinal sections from wildtype (C5+/+) (B) and C5 deficient (C5-/-) (C) mice subjected to hemorrhage. 
Using ANOVA with Newman-Keuls post hoc test, the asterisk indicates significant difference from $\mathrm{C}^{+}+/+$hemorrhage group $(p \leq 0.05)$.

Figure 4. Hemorrhage induces a complement-dependent inflammatory response. Ex vivo, intestinal $\mathrm{LTB}_{4}$ (A) and myeloperoxidase (B) production from each treatment group was determined by enzyme immunoassays as described in Materials and Methods. Each bar represents the average \pm SEM with four to six animals per group. Using ANOVA with NewmanKeuls post hoc test, the asterisk indicates significant difference from the wildtype treatment groups.

Figure 5. Administration of C5a receptor antagonist after hemorrhage prevents intestinal damage. $\mathrm{H}+\mathrm{E}$ intestinal sections of wildtype mice (B6) with (A, C) or without (B) C5a receptor antagonist (C5aRa) treatment were subjected to sham treatment (A) or hemorrhage (B,C). Mucosal injury (0-6) was determined as described in Materials and Methods (D). Using ANOVA with Newman-Keuls post hoc test, the asterisk indicates significant difference from C57Bl/6 hemorrhage group (B6 Hem).

\section{Figure 6. C5a receptor antagonist does not prevent C3 deposition on intestinal tissue.}

Wildtype mice were subjected to sham (A) or hemorrhage (B) prior to treatment with C5a receptor antagonist (C5aRa) and frozen intestinal sections were stained for C3 deposition as described in Materials and Methods. Original magnification is x200. Data are representative of three individual experiments. 
Figure 7. C5a receptor antagonist attenuates leukotriene B4 and myeloperoxidase

production in response to hemorrhage. Ex vivo, intestinal LTB4 (A) and myeloperoxidase (B) production by each treatment group was determined by enzyme immunoassays as described in Materials and Methods. Each bar is average \pm SEM with three to eight animals per group. Using ANOVA with Newman-Keuls post hoc test, asterisks indicate significant difference from the respective wildtype treatment groups (B6). 
Fig.1
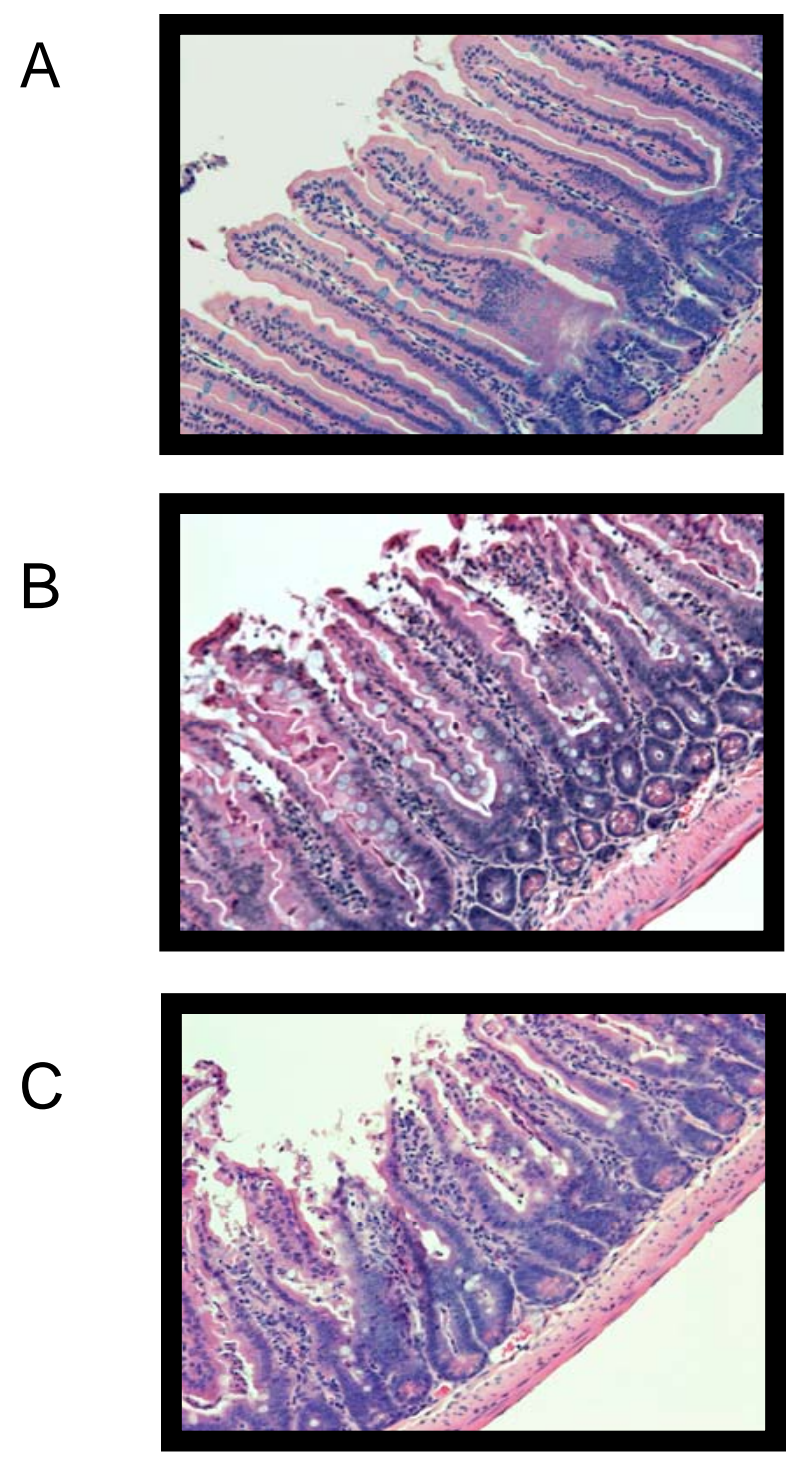

D.

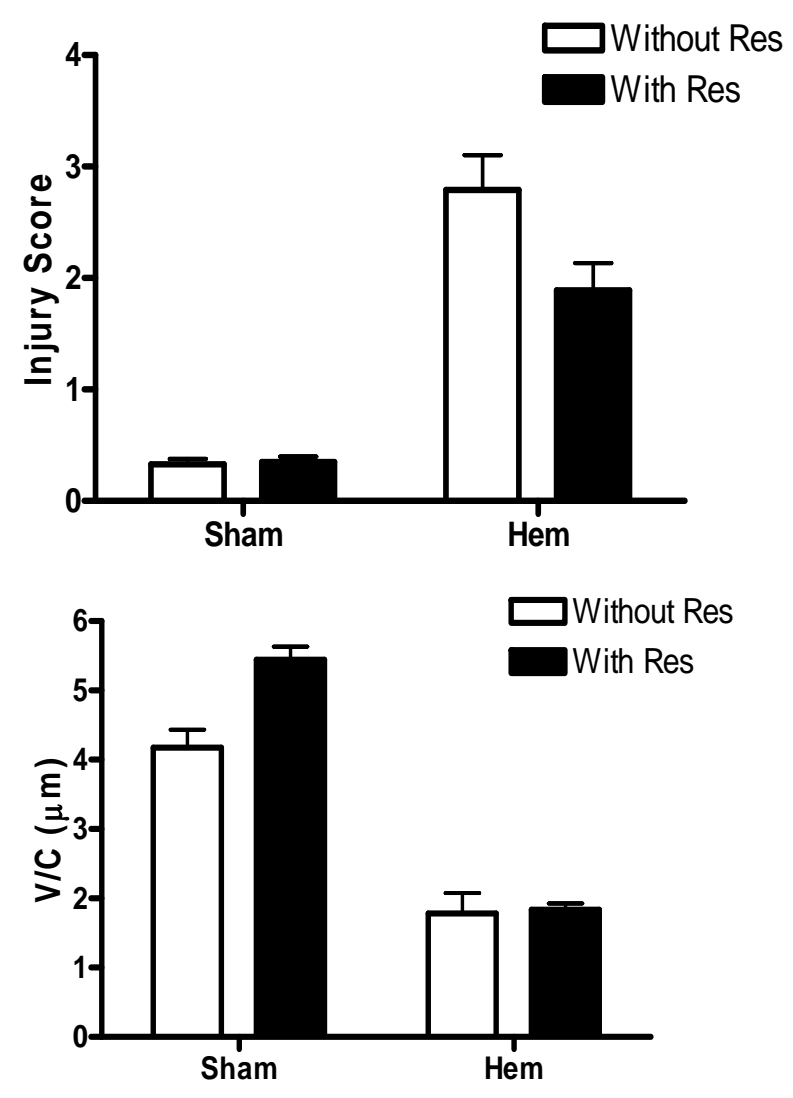


Fig. 2

A.

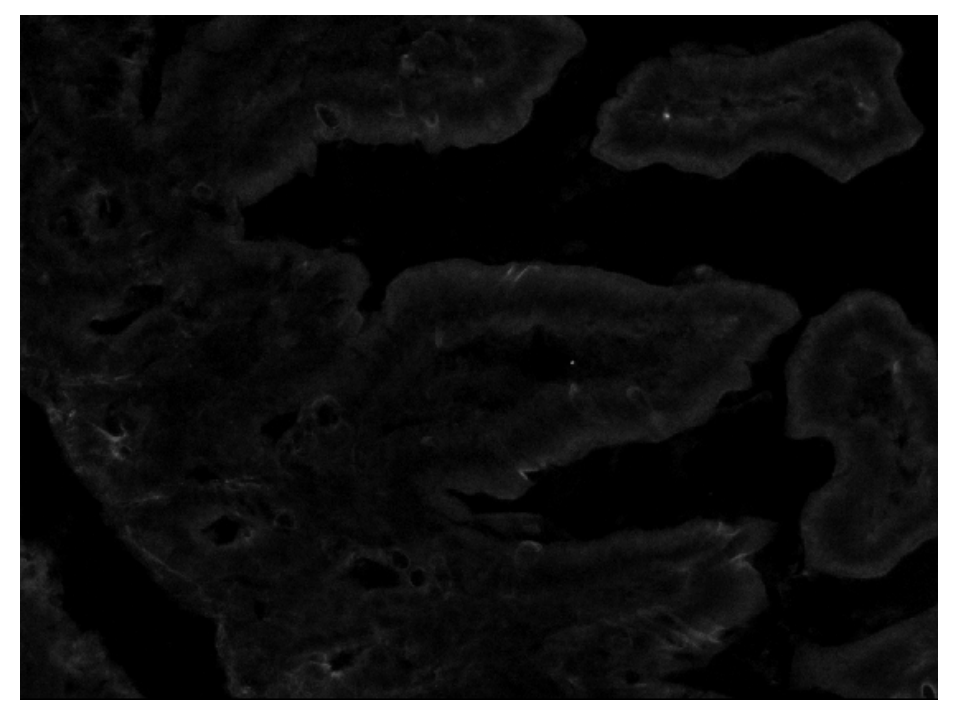

B.

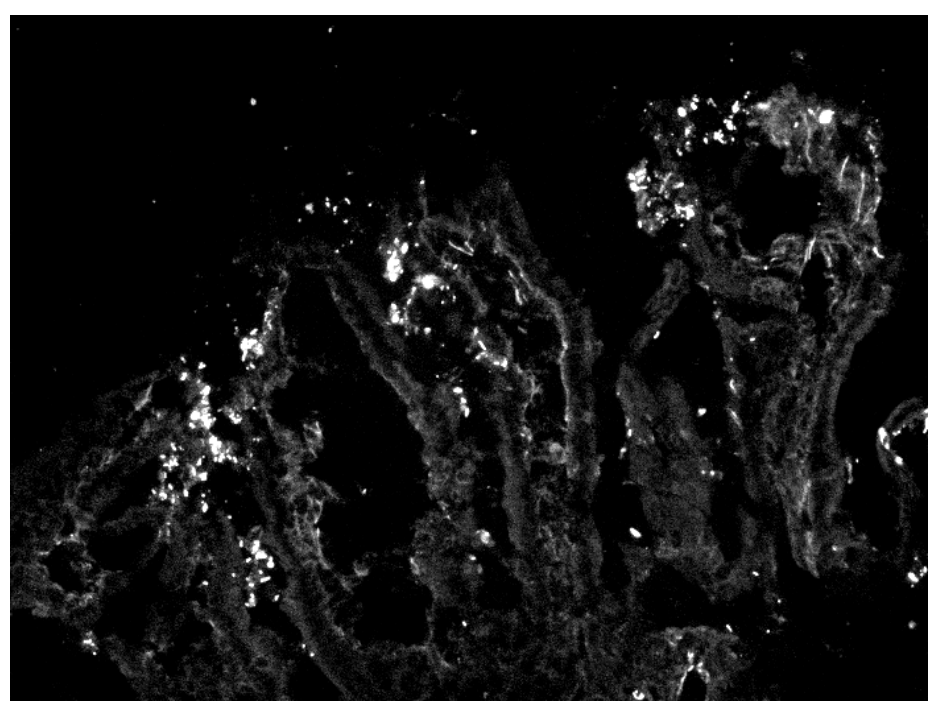




\section{Fig. 3}

A.

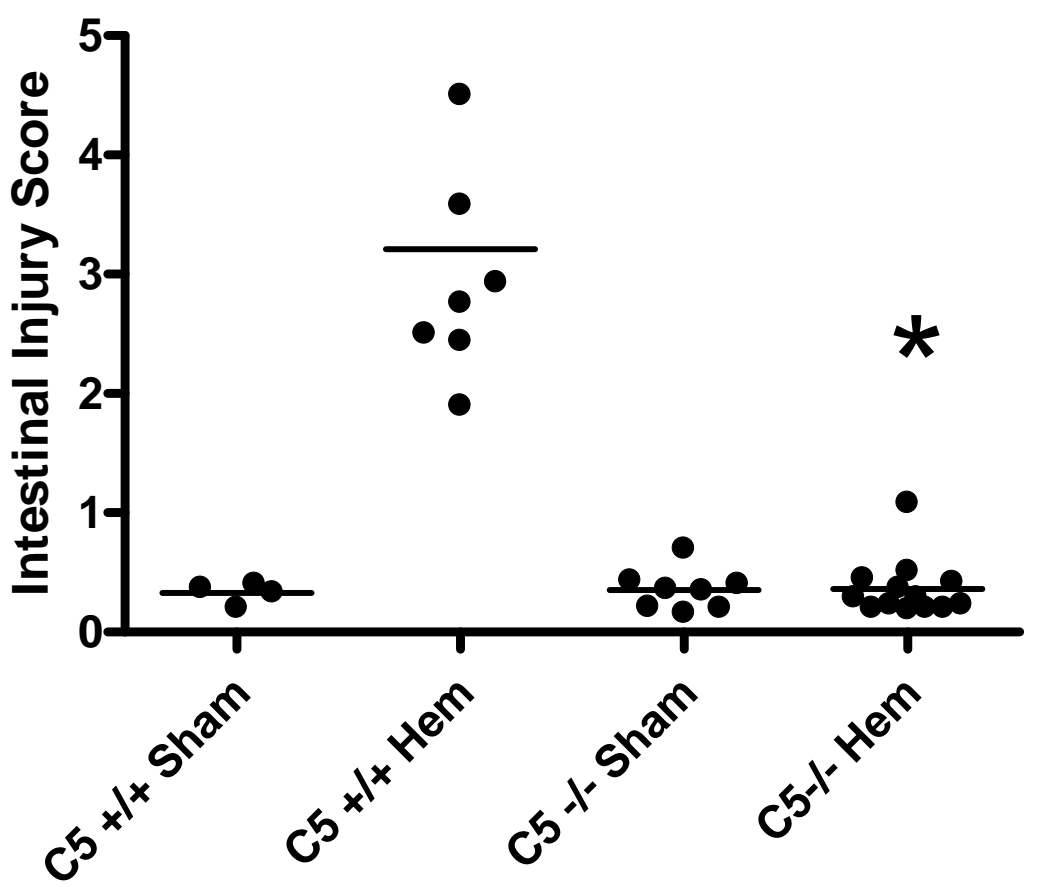

B. $\mathrm{C} 5+/+$

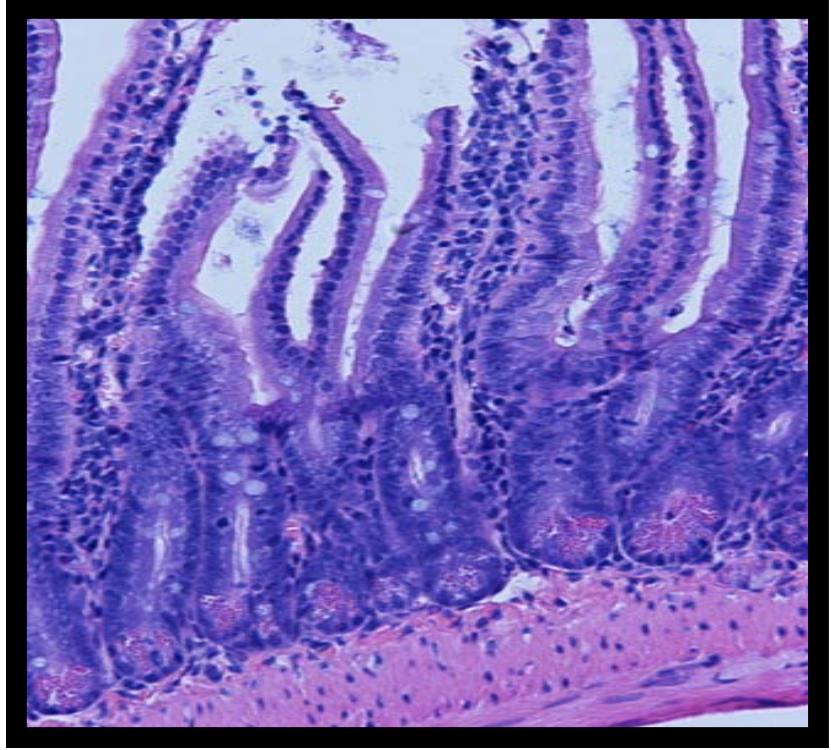

C. C5-/-

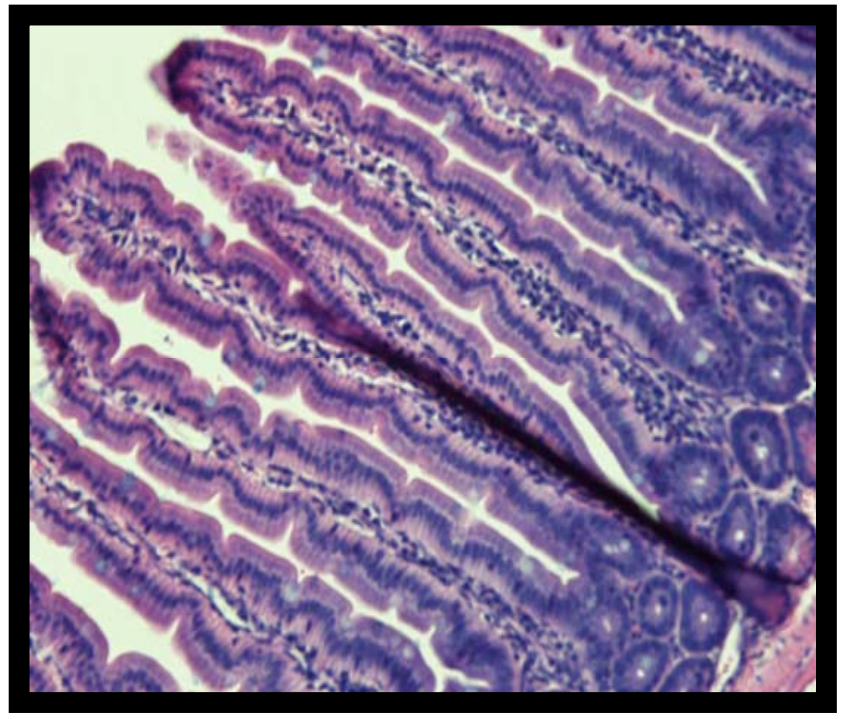




\section{Fig. 4}

A.

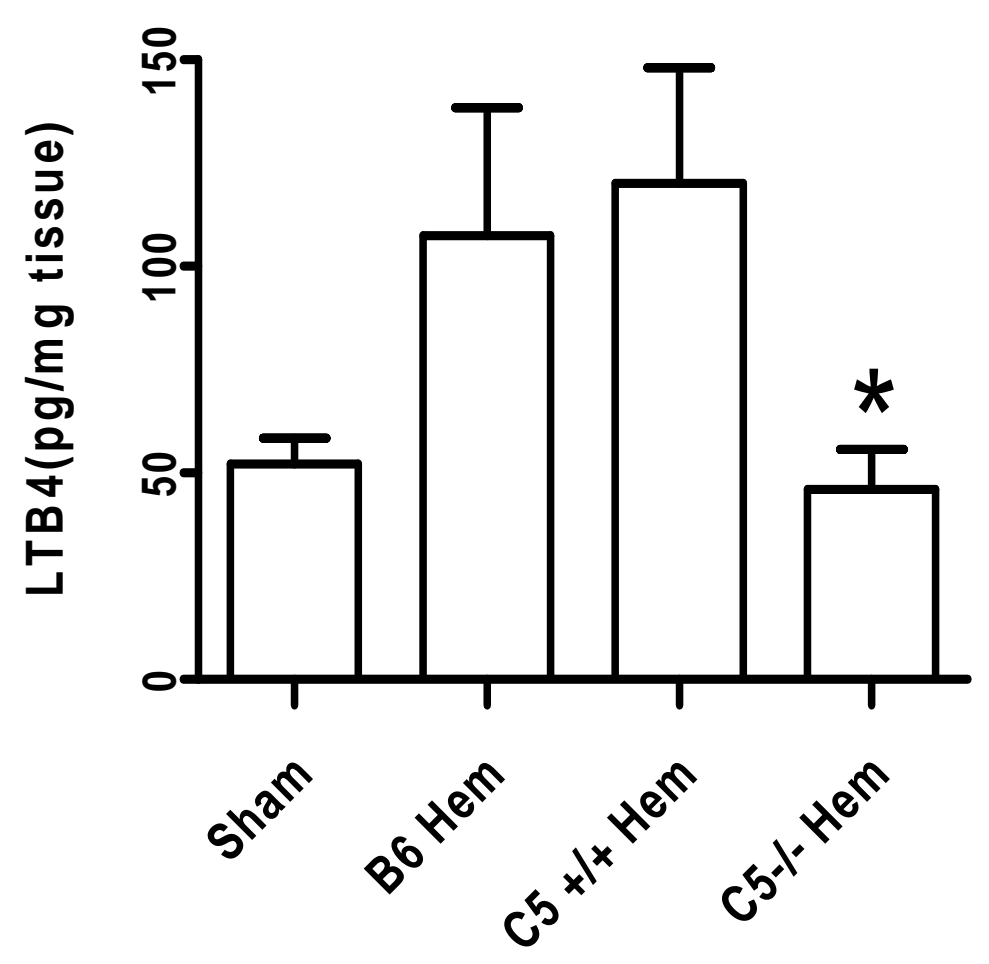

B.

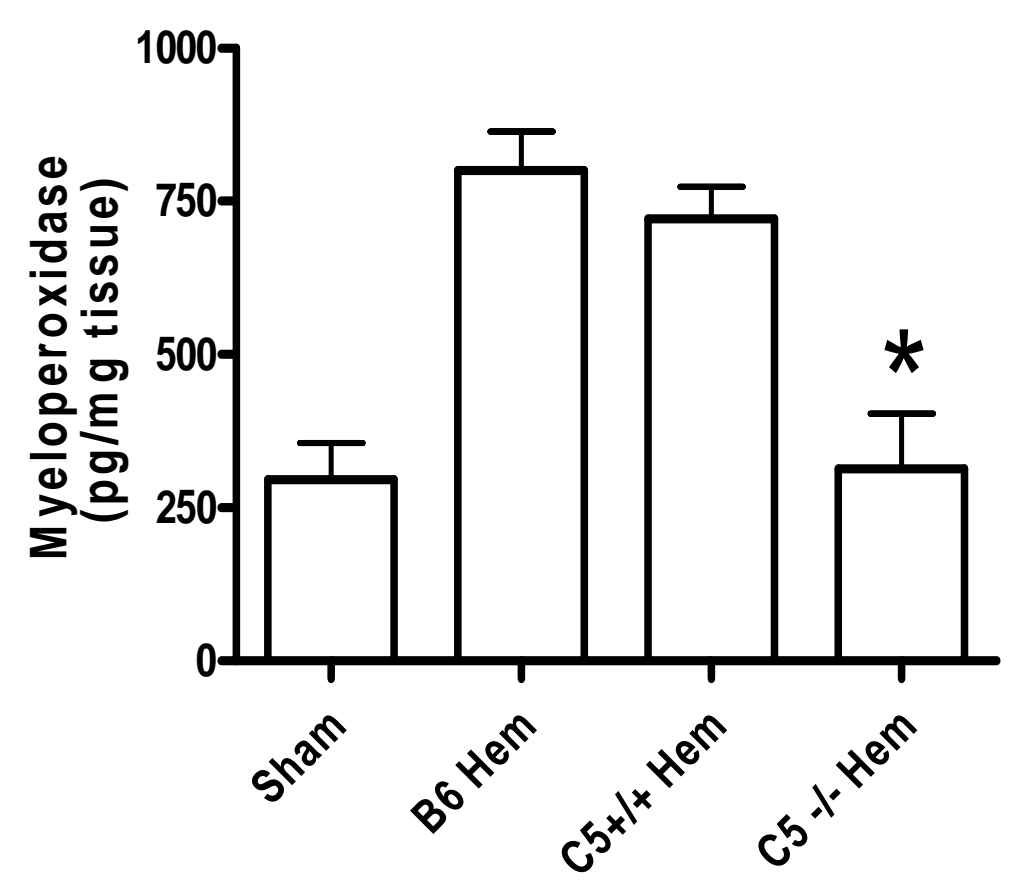




\section{Fig. 5}

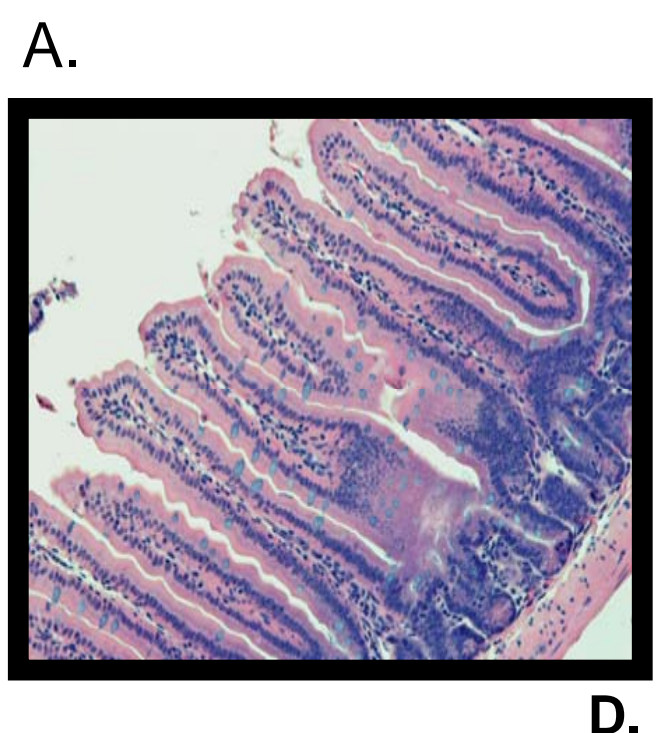

B.

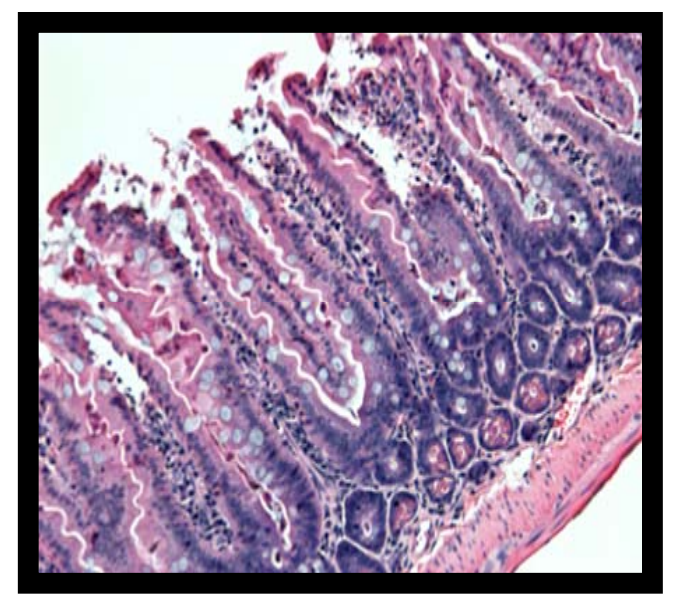

D.

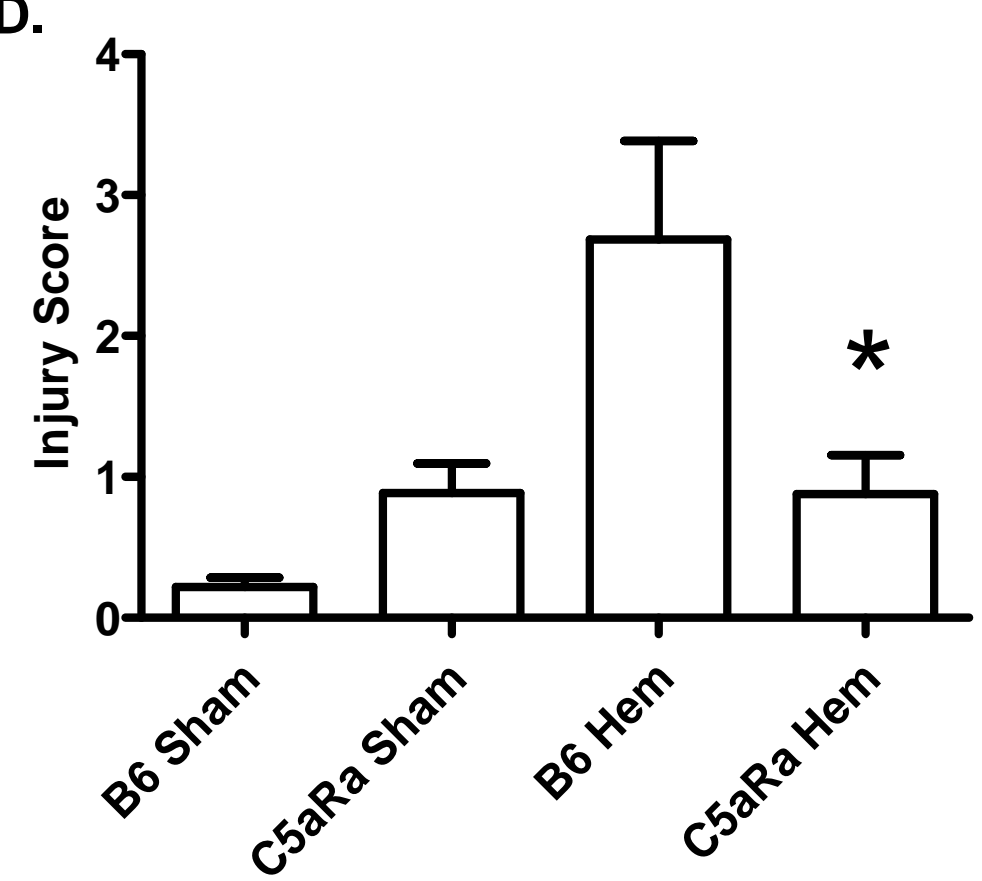

C.

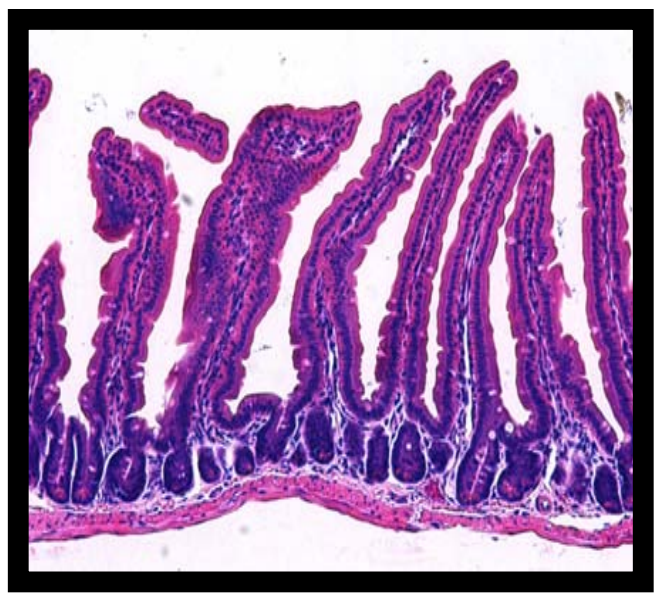


Fig. 6

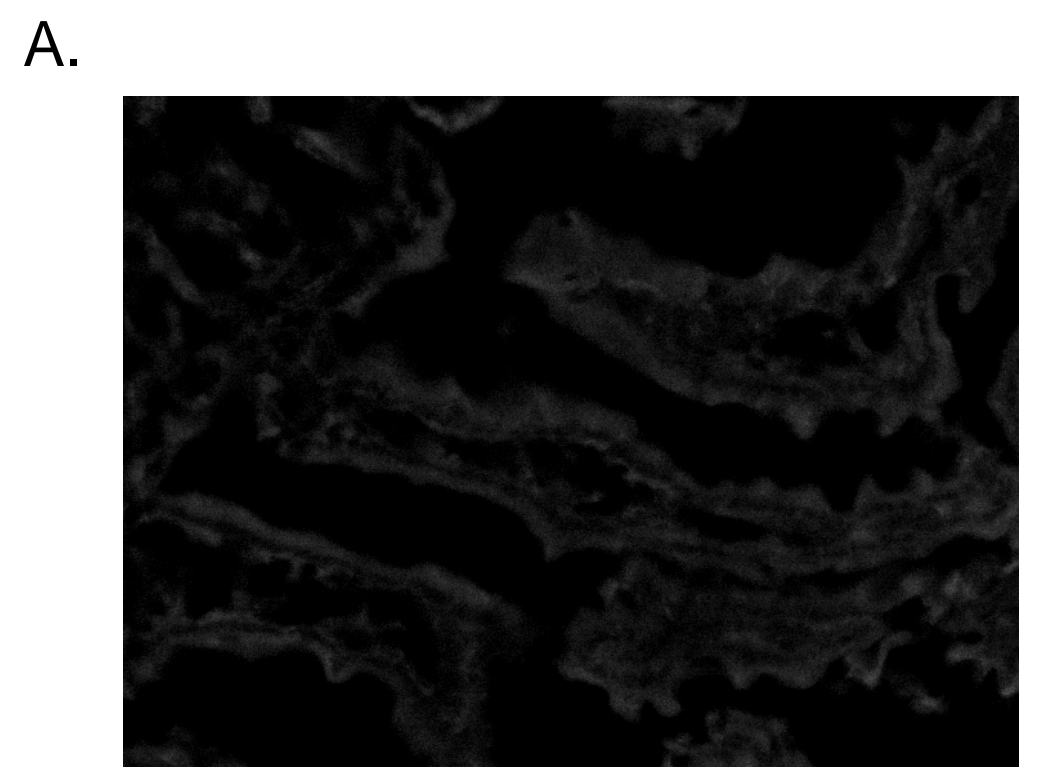

B.

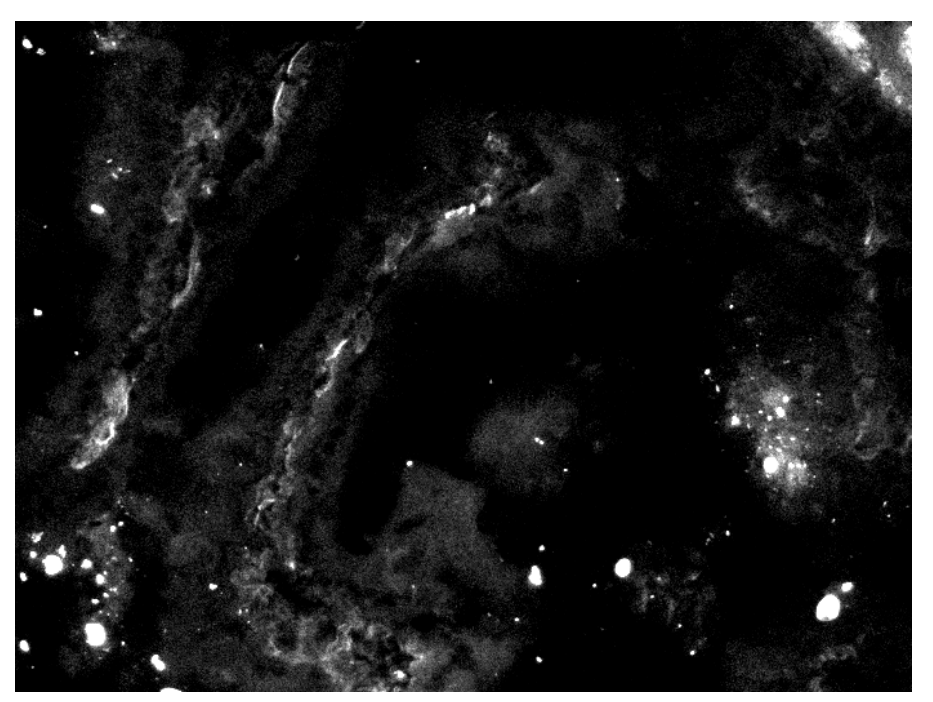


Fig. 7

A.

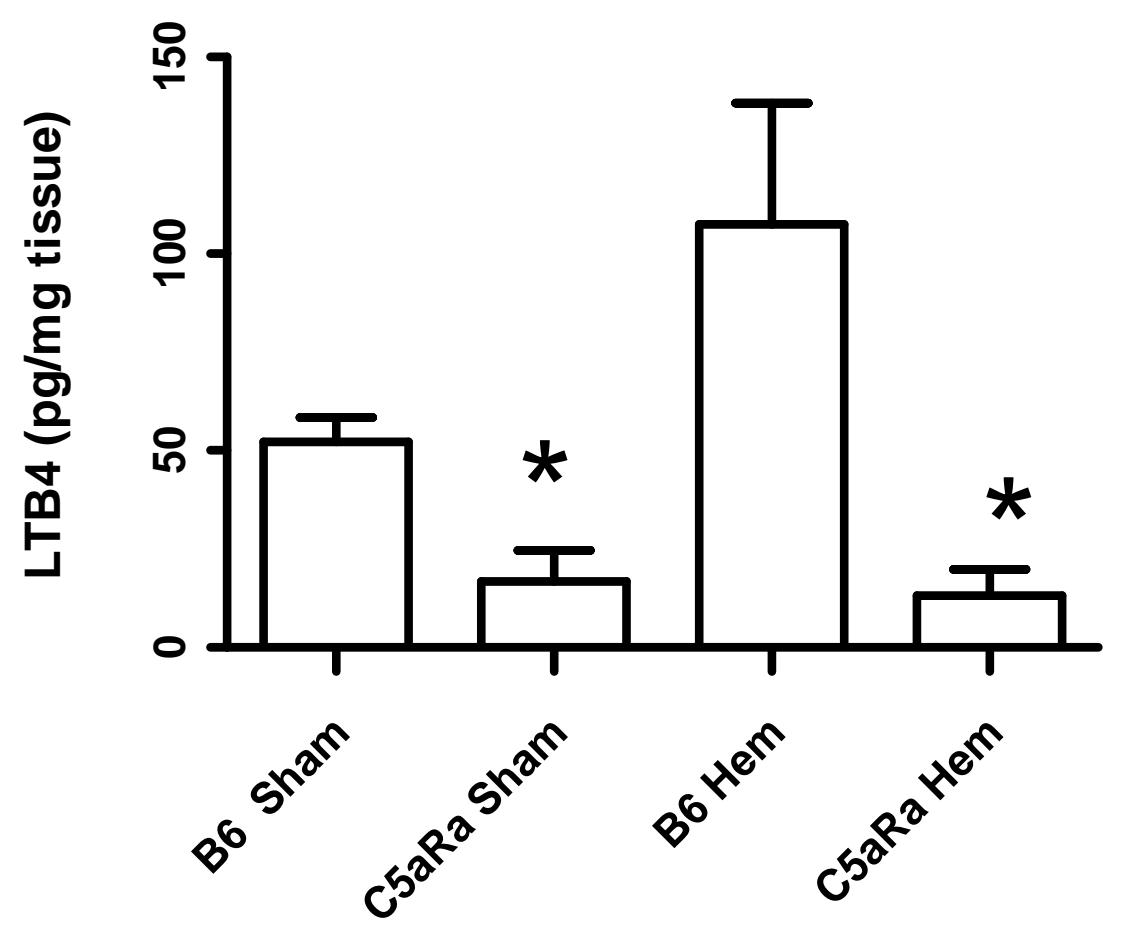

B.

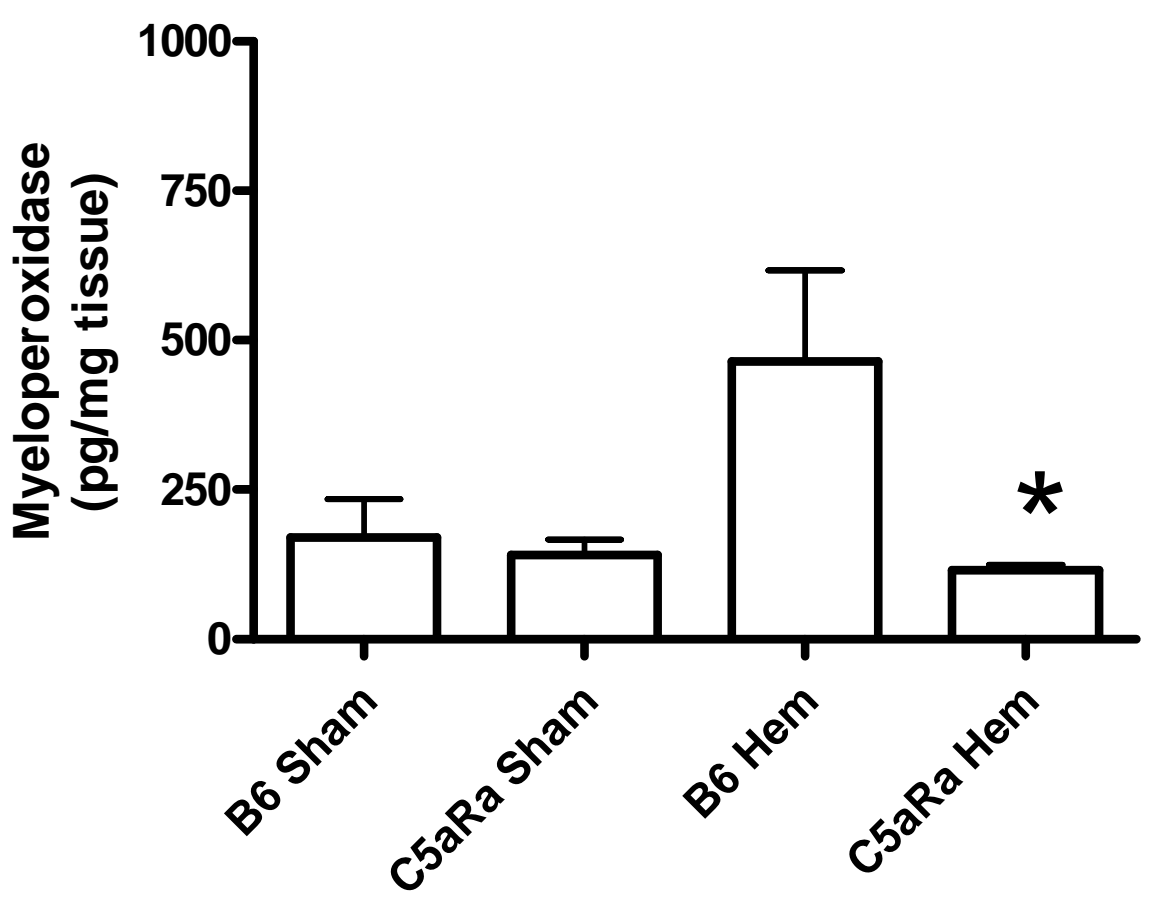

